\title{
Technical Note: Controlled experimental aquarium system for multi-stressor investigation of carbonate chemistry, oxygen saturation, and temperature
}

\author{
E. E. Bockmon ${ }^{1}$, C. A. Frieder ${ }^{2}$, M. O. Navarro ${ }^{2}$, L. A. White-Kershek ${ }^{3}$, and A. G. Dickson ${ }^{1}$ \\ ${ }^{1}$ Marine Physical Laboratory, Scripps Institution of Oceanography, University of California, San Diego, 9500 Gilman Drive, \\ La Jolla, CA 92093-0244, USA \\ ${ }^{2}$ Integrative Oceanography Division, Scripps Institution of Oceanography, University of California, San Diego, 9500 Gilman \\ Drive, La Jolla, CA 92093-0218, USA \\ ${ }^{3}$ Department of Biological Sciences, California State University, San Marcos, 333 Twin Oaks Valley Road, San Marcos, CA \\ 92096, USA
}

Correspondence to: E. E. Bockmon (ebockmon@ucsd.edu)

Received: 28 January 2013 - Published in Biogeosciences Discuss.: 25 February 2013

Revised: 17 June 2013 - Accepted: 4 August 2013 - Published: 11 September 2013

\begin{abstract}
As the field of ocean acidification has grown, researchers have increasingly turned to laboratory experiments to understand the impacts of increased $\mathrm{CO}_{2}$ on marine organisms. However, other changes such as ocean warming and deoxygenation are occurring concurrently with the increasing $\mathrm{CO}_{2}$ concentrations, complicating the understanding of the impacts of anthropogenic changes on organisms. This experimental aquarium design allows for independent regulation of $\mathrm{CO}_{2}$ concentration, $\mathrm{O}_{2}$ levels, and temperature in a controlled environment to study the impacts of multiple stressors. The system has the flexibility for a wide range of treatment chemistry, seawater volumes, and study organisms. Control of the seawater chemistry is achieved by equilibration of a chosen gas mixture with seawater using a Liqui$\mathrm{Cel}^{\circledR}$ membrane contactor. Included as examples, two experiments performed using the system have shown control of $\mathrm{CO}_{2}$ at values between approximately 500 and $1400 \mu \mathrm{atm}$ and $\mathrm{O}_{2}$ at values from 80 to $240 \mu \mathrm{mol} \mathrm{kg}{ }^{-1}$. Temperature has been maintained to $0.5^{\circ} \mathrm{C}$ or better in the range of $10-17^{\circ} \mathrm{C}$. On a weeklong timescale, the system has achieved variability in $\mathrm{pH}$ of less than $0.007 \mathrm{pH}$ units and in oxygen concentration of less than $3.5 \mu \mathrm{mol} \mathrm{kg} \mathrm{k}^{-1}$. Longer experiments, over a month in duration, have been completed with control to better than $0.08 \mathrm{pH}$ units and $13 \mu \mathrm{mol} \mathrm{kg} \mathrm{kg}^{-1} \mathrm{O}_{2}$. The ability to study the impacts of multiple stressors in the laboratory simultaneously, as well as independently, will be an important
\end{abstract}

part of understanding the response of marine organisms to a high- $\mathrm{CO}_{2}$ world.

\section{Introduction}

The amount of inorganic carbon in the oceans is increasing and the $\mathrm{pH}$ decreasing, a process commonly known as ocean acidification (Caldeira and Wickett, 2003). This is a consequence of the oceans taking up a proportion of the anthropogenic carbon dioxide emissions added to the atmosphere each year. In the past decade, ocean acidification has received increasing attention from the scientific community, particularly the impact of the expected changes in carbonate chemistry on organisms (Doney et al., 2009a). Experimental studies in the laboratory are an important part of this research (Doney et al., 2009b). While significant insight has been gained from these laboratory experiments, it has also become clear that the questions are not simple to answer, and that reasonable control of the experimental conditions can be challenging.

In 2010 EPOCA published a Guide to best practices for ocean acidification research and data reporting (Riebesell et al., 2010), which includes several chapters that are relevant to setting up experimental aquaria with the intent to control carbonate chemistry. Various options for modifying carbonate 
chemistry are suggested, which change the total dissolved inorganic carbon $\left(C_{\mathrm{T}}\right)$ of the seawater, the total alkalinity $\left(A_{\mathrm{T}}\right)$, or both simultaneously. A variety of experimental systems have been designed and used, with varying degrees of success, by researchers interested in controlling seawater carbonate chemistry in the laboratory. For example, several experiments have been performed by bubbling seawater directly with gas mixtures created by combining pure $\mathrm{CO}_{2}$ with ambient or $\mathrm{CO}_{2}$-stripped air to create an elevated partial pressure of $\mathrm{CO}_{2}: p\left(\mathrm{CO}_{2}\right)$ (Miller et al., 2009; Talmage and Gobler, 2009). One published system bubbles a custom gas mixture while monitoring $p\left(\mathrm{CO}_{2}\right)$ (Fangue et al., 2010); yet another uses acid additions to create constant $\mathrm{pH}$ seawater as determined by spectrophotometric measurements (McGraw et al., 2010). Some discussion has surrounded the various accepted methods of manipulation, and the differences in carbonate chemistry have been evaluated and found to be small (Gattuso and Lavigne, 2009; Schulz et al., 2009). Nevertheless, bubbling is often recommended as the "first choice" because it "exactly mimics carbonate chemistry changes occurring in the years to come" (Gattuso et al., 2010). However, direct bubbling with gas can lead to difficulties in sustaining phytoplankton cultures (Shi et al., 2009), and hence header tanks are often used for equilibration to eliminate the impact of bubbling on the experimental organism.

In addition to changes in the carbon parameters, other impacts of anthropogenic climate change on the ocean are expected. Temperatures in the upper $300 \mathrm{~m}$ of the oceans are rising (Lyman et al., 2010), and changes in stratification have occurred (Palacios et al., 2004). Also, oxygen saturation is expected to decrease as the oceans warm, stratify, and absorb carbon (Keeling et al., 2010; Shaffer et al., 2009). Predictions of the consequences of ocean acidification must consider synergistic effects between changing inorganic carbon parameters and changes to these other variables. Multistressor, or multi-variable, interactions have gained a lot of attention recently as researchers have begun to examine the many simultaneous impacts that climate change will have on organisms (Boyd, 2011; Pörtner et al., 2005). However, a review of marine climate change papers found that most were single-factor experiments, most often focusing on acidification alone (Wernberg et al., 2012). In particular, there is a need for experiments focusing on the combination of $\mathrm{CO}_{2}$ and $\mathrm{O}_{2}$ (Melzner et al., 2012; Pörtner et al., 2005). Changes in oxygen and $\mathrm{pH}$ are strongly, positively correlated in systems dominated by photosynthesis and respiration, as has been documented recently in coastal upwelling systems (Frieder et al., 2012; Paulmier et al., 2011); the implications for organisms simultaneously experiencing low $\mathrm{pH}$ and low oxygen levels in seawater are just starting to be investigated. The ability to modify $\mathrm{CO}_{2}$ and $\mathrm{O}_{2}$ levels independently in an experimental laboratory, in addition to temperature, will be critical to understanding the response of organisms that live in natural environments with these multiple stressors.
The Multiple Stressor Experimental Aquarium at Scripps (MSEAS) presented here is designed to enable such experiments and to facilitate the study of organisms under future ocean scenarios. The system is capable of independent manipulation and control of the inorganic carbon chemistry, oxygen levels, and temperature of the seawater in each tank. Additionally, the system is designed with flexibility so that it may be adapted for a variety of marine organisms and life stages. Finally, chemical data from two separate experiments are used to illustrate the stability and accuracy of the system.

\section{Methods}

\subsection{Carbon parameter control}

Achieving good control in an experimental laboratory setting is difficult, in part because the carbonate chemistry is complicated. Factors affecting control of the carbonate chemistry include gas exchange, temperature influences, and direct modification by the study organisms through processes such as photosynthesis, respiration, and calcification. Another obstacle is that measurement of the carbon parameters is neither simple nor inexpensive (Dickson et al., 2007; Dickson, 2010). Acid-base chemistry in clean seawater can be described using known equilibrium constants (given salinity, temperature, pressure, and the total boron/ salinity ratio), together with two other measured parameters (typically from $A_{\mathrm{T}}, C_{\mathrm{T}}, p\left(\mathrm{CO}_{2}\right)$, and $\left.\mathrm{pH}\right)$. (This is only strictly true when the other minor acid-base systems in the seawater (e.g., phosphate, silicate, ammonia, organic bases, etc.) do not contribute significantly to the alkalinity.) Consequently, for a particular seawater at a given temperature and salinity, it is only necessary to control two of these parameters to achieve control over the carbonate chemistry.

Controlling two parameters at once is not accomplished easily. However, by assuming a constant $A_{\mathrm{T}}$ in the aquarium, only a single parameter needs to be explicitly controlled (Dickson, 2010). Constant $A_{\mathrm{T}}$ is a reasonable assumption for the seawater system that supplies MSEAS; over a three-year period, the observed range of $A_{\mathrm{T}}$ for the seawater system was $50 \mu \mathrm{mol} \mathrm{kg}^{-1}$ (Fig. 1). This would change $\mathrm{pH}$ calculated from $A_{\mathrm{T}}$ at a constant $p\left(\mathrm{CO}_{2}\right)$ by less than $0.01 \mathrm{pH}$ units. More often $A_{\mathrm{T}}$ is similar from one day to the next, showing large changes over months, rather than days. Consequently, the assumption of constant $A_{\mathrm{T}}$ only leads to small errors in the understanding of the carbonate chemistry when paired with controlled $p\left(\mathrm{CO}_{2}\right)$, and thus serves as a reasonable assumption for this experimental system.

However, some care must be taken to ensure that the assumption of constant $A_{\mathrm{T}}$ remains true in an aquarium setting. Organisms continually modify the chemistry of their environment. For $A_{\mathrm{T}}$, this usually means calcification or the assimilation and remineralization of other nutrients and ions (for further discussion, see Wolf-Gladrow et al., 2007). To 


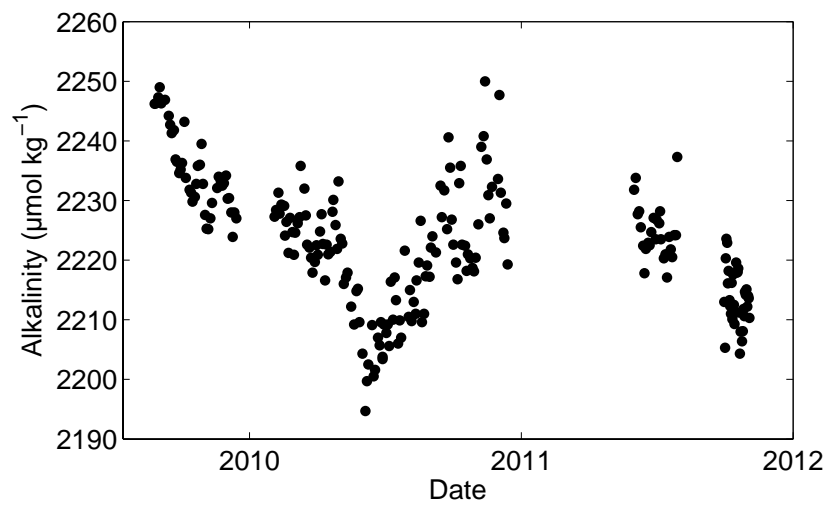

Fig. 1. Measured total alkalinity $\left(\mu \mathrm{mol} \mathrm{kg}{ }^{-1}\right)$ in the Scripps Institution of Oceanography seawater system over several years. Discrete samples were poisoned for later analysis. The mean is 2223 and the standard deviation is $11 \mu \mathrm{mol} \mathrm{kg}-1$.

maintain $A_{\mathrm{T}}$ levels throughout the duration of the experiment, some action must be taken to counteract these modifications. The most straightforward solution is the continual addition of new seawater to the tanks, which replenishes $A_{\mathrm{T}}$. Sufficient seawater replacement, depending on the organisms and their respective biomasses in the aquaria, will guarantee that the $A_{\mathrm{T}}$ in each tank reflects the assumed constant $A_{\mathrm{T}}$ of the seawater supply system.

Alkalinity is particularly useful as a control variable for carbonate chemistry in an ocean acidification experimental laboratory. Not only is it conservative with respect to mixing and not affected by changes in temperature, but also the addition or removal of $\mathrm{CO}_{2}$ gas from seawater does not change $A_{\mathrm{T}}$. This allows for modification of the total amount of $\mathrm{CO}_{2}$ (and of $\mathrm{O}_{2}$ ) in the seawater as a means to control a second parameter without invalidating the assumption of constant $A_{\mathrm{T}}$. In MSEAS, the second parameter is controlled by reacting a gas of a particular $\mathrm{CO}_{2}$ and $\mathrm{O}_{2}$ content with seawater using a membrane contactor, which allows a desired $p\left(\mathrm{CO}_{2}\right)$ and oxygen percent saturation to be achieved. This direct equilibration of a known gas with seawater has the same effect on carbonate chemistry as if bubbling had been used to modify the seawater sample.

\subsection{Apparatus}

To achieve the desired chemistry in MSEAS, a gas mixture is equilibrated with seawater using a Membrana Liqui-Cel ${ }^{\circledR}$ $2.5 \times 8$ Extra-Flow membrane contactor for each aquarium (Fig. 2). The desired gas composition $\left(\mathrm{N}_{2}, \mathrm{O}_{2}, \mathrm{CO}_{2}\right)$ is mixed from individual gas cylinders using Omega ${ }^{\circledR}$ mass flow controllers (FMA 5418 0-5 SLM; FMA 5411 0-2 SLM; and FMA 5402 0-10 sccm, respectively). The mass flow controllers are operated by a laptop running NI LabVIEW ${ }^{\mathrm{TM}}$ software with communication using a voltage generating NI 9265 4-Channel Analog Output Module ${ }^{\mathrm{TM}}$ combined with an NI USB-9162 Single Module Carrier ${ }^{\mathrm{TM}}$. Mass flow controller function is monitored using a NI USB-6210 Multifunction $\mathrm{DAQ}^{\mathrm{TM}}$ (Fig. 2). Mixing individual gases gives the user complete control over both the $\mathrm{CO}_{2}$ and $\mathrm{O}_{2}$ concentrations. After the three gases mix in the desired proportions, the line is split, providing an identical gas mixture to two or more replicate tanks. Currently the system is designed with two sets of three mass flow controllers, allowing for two independent treatment levels.

A submerged MARINELAND ${ }^{\circledR}$ Maxi-Jet 1200 Power Head pumps seawater from each treatment tank through a $5 \mu \mathrm{m}$ filter and then through the tank's associated Liqui-Cel membrane contactor. The gas mixture is introduced to the Liqui-Cel in the opposite direction, enhancing equilibration. The seawater is returned to the corresponding treatment tank, and the gas flows to waste (Fig. 2). Despite this continuous recirculation of the treatment seawater, it is not expected that the seawater will equilibrate perfectly with the gas phase. Fluctuations in temperature, flow rates, and in the degree of disequilibrium brought about by changes in the composition of the seawater in the tank due to gas exchange or biological processes all work against achieving complete equilibrium. Nevertheless, as will be seen, a reasonable degree of control can be achieved.

The temperature of each tank is maintained with a titanium coil through which temperature-controlled water flows from a Thermo Scientific NESLAB ${ }^{\mathrm{TM}}$ RTE 7 Refrigerated Bath. The system design allows the seawater in each aquarium to be exchanged in a flow-through mode, where raw seawater is added continually at a slow rate, maintaining $A_{\mathrm{T}}$ levels. The excess seawater overflows, removing organism waste. This rate of overturning must be optimized, and will be organism and biomass dependent. Although the system was originally designed with a large, $50 \mathrm{~L}$ tank in mind, the size of the treatment tank is easily exchangeable. Several of the experiments performed have used much smaller volumes to fit the experimental organism better and to maximize control over the chosen parameters. The size of the tank, and therefore the volume of water needing to be equilibrated, must be chosen for each experimental organism and desired biomass. Smaller volumes of water will recirculate through the membrane and interact with the gas more often, leading to better control.

Equilibration between the gas and seawater using the Liqui-Cel is done independently for each replicate aquarium tank, so there is no mixing of treated seawater. The only shared part of any replicate is the gas composition and the original source water. An often-used technique in ocean acidification experiments involves modifying the composition of a header tank that then provides identical source water to many replicate tanks. In these systems, the actual composition of an individual tank can diverge from that of the source water due to gas exchange or biological processes. By modifying the composition of individual tanks directly, we hope to mitigate such divergences and achieve better control. 


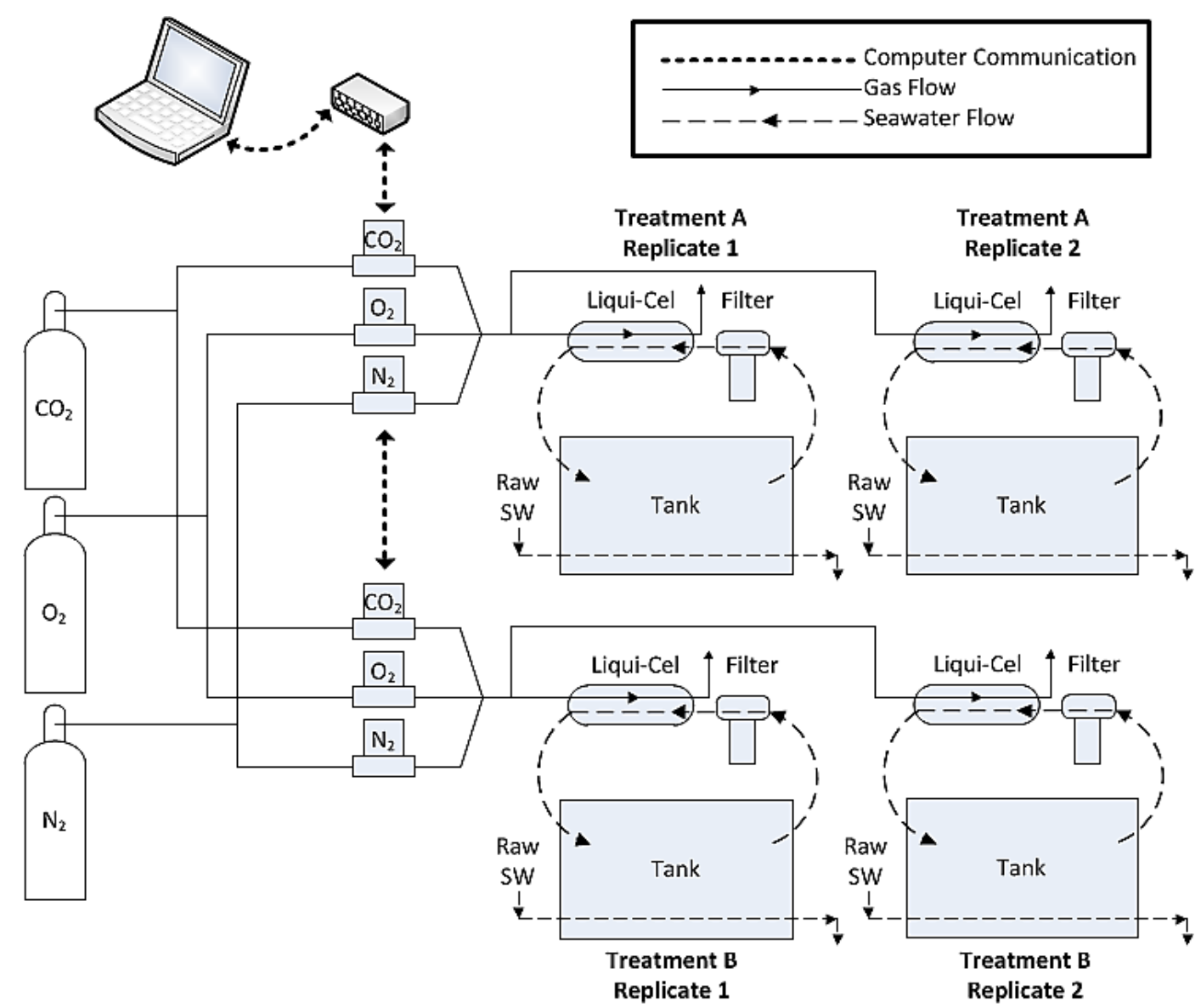

Fig. 2. Schematic of the aquarium control system. Solid lines indicate gas tubing and flow, and thin dashed lines indicate seawater tubing and flow. Thick dashed lines represent data communication between instruments.

One of the primary advantages of MSEAS, is that it allows the user to choose a desired $\mathrm{CO}_{2}$ and $\mathrm{O}_{2}$ composition, within a large range. The $\mathrm{CO}_{2}$ level of the gas mixture can be chosen by the user to be any value between 0 and $5000 \mathrm{ppm}$, although the maximum $p\left(\mathrm{CO}_{2}\right)$ of any experiment performed to date is approximately $1500 \mu \mathrm{atm}$. Barry et al. (2010) includes suggestions of $\mathrm{CO}_{2}$ levels for ocean acidification laboratory experiments; the recommendation for a two treatment system is for one treatment near a "present-day" (mid-2008) atmospheric value of $385 \mathrm{ppm}$ and the other at a "future" value of $750 \mathrm{ppm}$. MSEAS is well suited to perform experiments at these specified values, but also has the advantage of flexibility in terms of its target $\mathrm{CO}_{2}$. This is especially valuable, in that it easily allows investigation of environments that are not at equilibrium with the atmosphere. For example, the coastal region of western North America experiences upwelling events, in which seawater already elevated in $\mathrm{CO}_{2}$ flows onto parts of the continental shelf (Feely et al., 2008).

\section{Assessment and discussion}

The usefulness and capability of this system is demonstrated by the experiments performed to date. Two of these experiments are described below as examples of the stability that can be maintained - one a week long, the other lasting longer than a month. Both experiments modified the $\mathrm{CO}_{2}$ and $\mathrm{O}_{2}$ of the seawater for each treatment and were performed at different temperatures. Discrete samples for $A_{\mathrm{T}}, \mathrm{pH}$, and $\mathrm{O}_{2}$ were taken daily during the experiments and analyzed at Scripps Institution of Oceanography. $A_{\mathrm{T}}$ samples were poisoned with saturated mercuric chloride and stored for later analysis which was done by open-cell titration (Dickson et al., 2007). Discrete pH samples were analyzed spectrophotometrically (Dickson et al., 2007) on the same day as sampling. Values are reported at the in situ temperature and on the total $\mathrm{pH}$ scale. Discrete oxygen samples were pickled immediately and analyzed within a few days by Winkler titration (Dickson, 1996). Temperature was monitored every five minutes in all tanks by HOBO Pendant ${ }^{\mathrm{TM}}$ Temperature/Light Data Loggers. 
Table 1. Average \pm standard deviation for chemical parameters during experiment $\mathrm{M} 7$. The $p\left(\mathrm{CO}_{2}\right), \Omega_{\text {calcite }}$, and $\Omega_{\text {aragonite }}$ reported here were calculated using CO2calc (Robbins et al., 2010) with dissociation constants from Mehrbach et al. (1973) as refit by Dickson and Millero (1987). For most values $n=8$, except for oxygen for which some samples from each tank were lost (see Fig. 3).

\begin{tabular}{rllllllll}
\hline & $\begin{array}{l}\text { Temp } \\
\left({ }^{\circ} \mathrm{C}\right)\end{array}$ & Salinity & $\begin{array}{l}\text { Alkalinity } \\
\left(\mu \mathrm{mol} \mathrm{kg}{ }^{-1}\right)\end{array}$ & $\begin{array}{l}\mathrm{pH}_{(\mathrm{in} \mathrm{situ)}} \\
\text { total scale }\end{array}$ & $\begin{array}{l}\text { Oxygen } \\
\left(\mu \mathrm{mol} \mathrm{kg}^{-1}\right)\end{array}$ & $\begin{array}{l}\text { Calculated } p\left(\mathrm{CO}_{2}\right) \\
(\mu \mathrm{atm})\end{array}$ & $\begin{array}{l}\text { Calculated } \\
\Omega_{\mathrm{Calcite}}\end{array}$ & $\begin{array}{l}\mathrm{Calculated} \\
\Omega_{\text {Aragonite }}\end{array}$ \\
\hline Treatment A & & & & & & & & \\
Replicate 1 & $17.2 \pm 0.3$ & $33.65 \pm 0.01$ & $2249.3 \pm 6.1$ & $7.924 \pm 0.004$ & $230.9 \pm 2.2$ & $546.1 \pm 5.8$ & $3.09 \pm 0.03$ & $1.99 \pm 0.02$ \\
$\quad$ Replicate 2 & $17.2 \pm 0.2$ & $33.64 \pm 0.01$ & $2250.4 \pm 5.9$ & $7.905 \pm 0.007$ & $227.7 \pm 1.3$ & $574.6 \pm 9.5$ & $2.96 \pm 0.05$ & $1.91 \pm 0.03$ \\
Treatment B & & & & & & & & \\
Replicate 1 & $17.0 \pm 0.4$ & $33.66 \pm 0.01$ & $2254.1 \pm 7.0$ & $7.619 \pm 0.007$ & $86.2 \pm 3.4$ & $1188.4 \pm 17.7$ & $1.64 \pm 0.03$ & $1.05 \pm 0.02$ \\
Replicate 2 & $17.2 \pm 0.3$ & $33.65 \pm 0.01$ & $2250.5 \pm 4.0$ & $7.612 \pm 0.005$ & $83.9 \pm 2.7$ & $1209.8 \pm 15.8$ & $1.62 \pm 0.02$ & $1.04 \pm 0.01$ \\
\hline
\end{tabular}

\subsection{Experiment M7}

A week-long experiment was performed on mussel larvae (Mytilus galloprovincialis) with one treatment of $\mathrm{pH}$ and oxygen levels, typical of a present-day California coastal upwelling environment (Frieder et al., 2012), and the other with lower $\mathrm{pH}$ and oxygen levels indicative of a future upwelling environment. For this experiment, the treatment tanks were round $7.5 \mathrm{~L}$ buckets with lids. The larvae were protected from the flowing seawater recirculation by containment in a smaller nested bucket that freely exchanged seawater with the main tank. Both treatments were held at an average temperature of $17.2^{\circ} \mathrm{C}$. Alkalinity varied only slightly over the week, and consequent control of $\mathrm{pH}$ and oxygen levels were very good (Table 1 and Fig. 3).

In addition to the discrete sampling, a Honeywell Durafet ${ }^{\circledR}$ $\mathrm{pH}$ sensor was used throughout the experiment to monitor the carbonate chemistry on short timescales, switching between tanks daily. The Durafet sensor data in Fig. 4 show day-long variability in $\mathrm{pH}$, beginning each day when the sensor's location was changed. Four consecutive examples are given, one from each tank. Some fluctuation is seen, possibly a result of temperature changing throughout the day, or a respiration signal in response to the $12 \mathrm{~h}$ light cycle. This fluctuation is possible due to the somewhat passive approach to controlling the carbonate chemistry in the current system design, supplying a constant composition gas mixture to each LiquiCel. Such fluctuations could be damped if a more active approach to $\mathrm{pH}$ control was taken, using information gathered by chemical sensors in the tanks as a basis to adjust the gas composition supplied to the Liqui-Cels, to compensate for divergences from the desired seawater chemistry. Adjustments to the gas mixture would not only dampen or eliminate the small diurnal signal seen, but would also ensure that large changes in seawater chemistry did not occur over the course of the experiment.
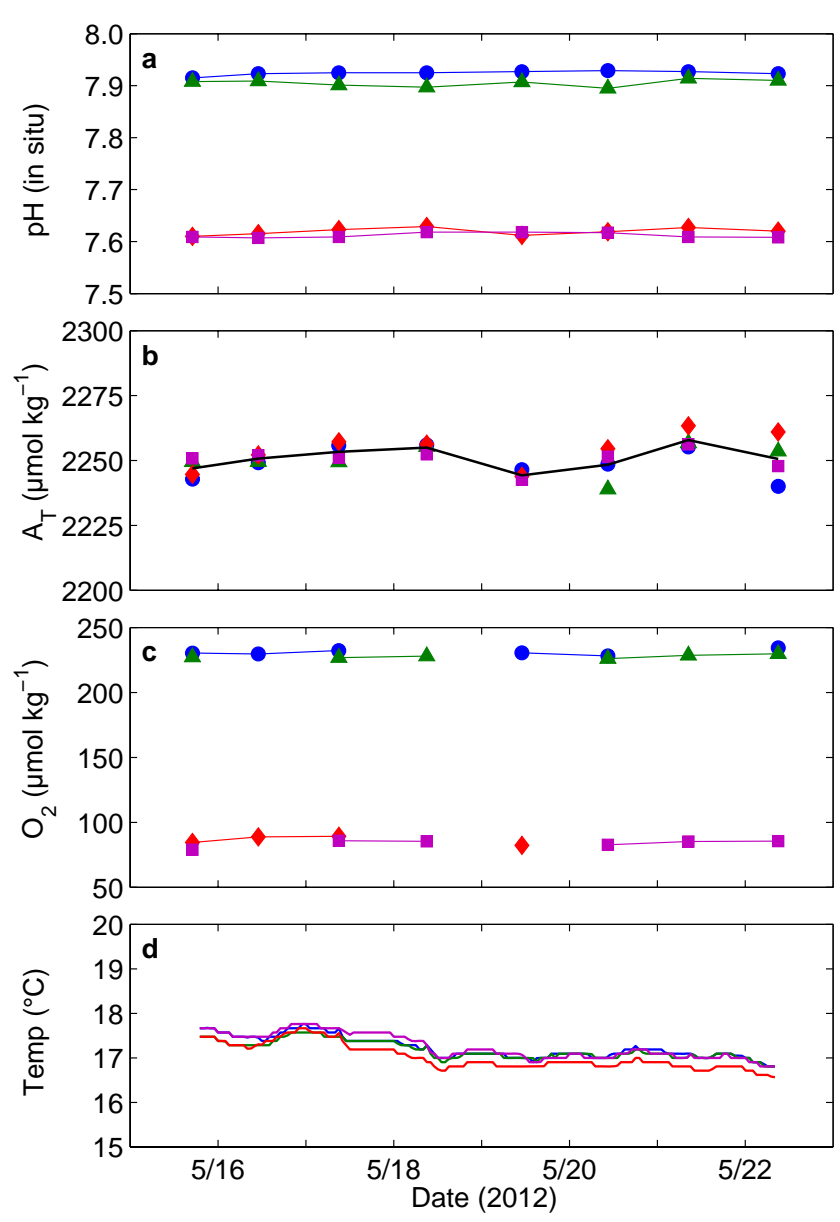

Fig. 3. Measured data from experiment M7. (a) $\mathrm{pH}$ : total $\mathrm{pH}$ scale; (b) $A_{\mathrm{T}}$ : the solid black line connects the daily average for all four tanks; (c) oxygen; and (d) temperature. Symbols indicate discrete samples: Treatment A Replicate 1 (blue circles), Treatment A Replicate 2 (green triangles), Treatment B Replicate 1 (red diamonds), and Treatment B Replicate 2 (purple squares). 


\subsection{Experiment S32}

The system can be used on much longer timescales than a week, demonstrated by a 32-day experiment investigating the impacts of varied $\mathrm{pH}$ and oxygen levels on squid embryos (Doryteuthis opalescens). The experiment was performed in square $50 \mathrm{~L}$ insulated tanks, with the squid egg capsules attached to the bottom. Some turbulence was caused by the recirculation of the seawater for equilibration. Target $\mathrm{pH}$ and oxygen levels were chosen based on values recorded at a location near Scripps (Nam et al., 2011). For this experiment, low $\mathrm{pH}$ and high oxygen levels were paired in one treatment, and high $\mathrm{pH}$ and low oxygen levels in the other, to attempt to understand organismal responses to the individual parameters. This is in contrast to experiment M7, which paired low oxygen and low $\mathrm{pH}$, thus demonstrating the system flexibility and independent control of chosen seawater chemistry. The longer duration of this experiment reflects a growing need in the scientific community to understand the effects of chronic exposure to low $\mathrm{pH}$ on organisms. Results from discrete samples indicate adequate control for a successful biological experiment, even over this extended period (Table 2 and Fig. 5). However, there are clear discrepancies from target values and both gradual and abrupt changes occur during the experiment, some of which are easily explained.

The control of the seawater chemistry in MSEAS is based on the mole fraction of $\mathrm{CO}_{2}$ and $\mathrm{O}_{2}$ in the gas that is supplied to the Liqui-Cel for equilibration. Any changes in that mole fraction will be apparent in the resulting seawater chemistry. Throughout experiment S32 several deliberate changes were made to the control parameters: on 11 March 2012, the amount of oxygen in the gas mixture was increased from $5.4 \%$ to $6.9 \%$ of the total gas flow in Treatment A, and from $19.7 \%$ to $20.1 \%$ in Treatment B. The subsequent increase in the dissolved oxygen content of the seawater on that day is apparent in Fig. 5. Similarly, the $\mathrm{CO}_{2}$ fraction in the gas of Treatment B was increased from $1500 \mathrm{ppm}$ to $1600 \mathrm{ppm}$ during the experiment, likely causing the decrease in $\mathrm{pH}$ seen. The abrupt increase in seawater temperature of all tanks beginning 23 March 2012 results from a deliberate increase in the temperature setting of the thermostat baths. These changes are reflected in Table 2 by the much larger standard deviations for $\mathrm{pH}$, oxygen level, and temperature than were observed during experiment M7. The reason for the significant $\mathrm{pH}$ decrease in Treatment A Replicate 2 on 24 March 2012, which is then maintained the rest of the experiment, is unknown, although it may indicate problems with the particular Liqui-Cel that was in use on the tank.

Probably the easiest way to improve the consistency of $\mathrm{pH}$ and oxygen levels in this system would be to improve the seawater temperature control. In both example experiments, the temperature of the treatment seawater in the tanks was influenced in part by the room air temperature, which was strongly influenced by the San Diego weather. This effect was much stronger in S32, with a daily seawater tem-

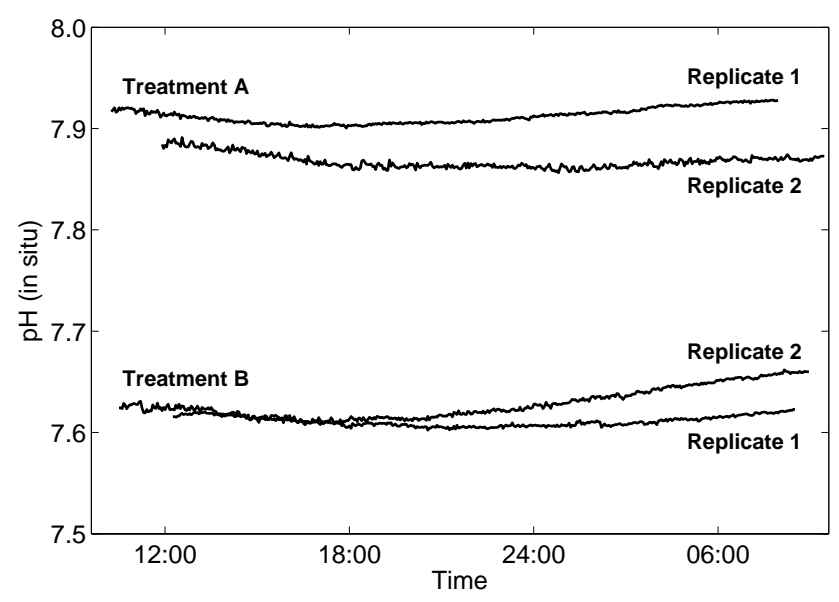

Fig. 4. $\mathrm{pH}$ recorded by a single Durafet sensor. The sensor was used to monitor each of the four tanks on four consecutive days. Data begins and ends at the time the sensor was moved each day, allowing for sensor equilibration once placed in the tank.

perature cycle of approximately $0.5^{\circ} \mathrm{C}$ occurring throughout most of the experiment. This likely contributed to the poorer control over the carbonate chemistry compared to experiment M7. Such temperature changes strongly influence the carbonate parameters; a $1{ }^{\circ} \mathrm{C}$ change in temperature causes about a 0.015 change in $\mathrm{pH}$ and a $20-50 \mu$ atm change in $p\left(\mathrm{CO}_{2}\right)$. Between experiments $\mathrm{S} 32$ and $\mathrm{M} 7$, the location of MSEAS was moved from an uninsulated building (located at the Birch Aquarium at Scripps) to a more protected location (the Scripps Experimental Aquarium facility). This change in location likely helps account for the difference in seawater temperature control, as there was less room temperature variability in the second location.

\section{Conclusions}

MSEAS will be useful to help elucidate responses of organisms to expected future ocean scenarios, which involve changes to multiple physical and chemical parameters. The system design allows for manipulation of any one or multiple of the three control parameters: $\mathrm{CO}_{2}$ concentration, $\mathrm{O}_{2}$ levels, and temperature. This independent control is a potentially useful experimental approach for investigating drivers underlying organismal responses. The automated prototype presented here is easily scalable to larger numbers of replicates by splitting the gas line (provided one ensures adequate gas flow) and adding Liqui-Cels for each tank. Implementation of additional simultaneous treatments requires more mass flow controllers for creation of a separate gas composition, in addition to Liqui-Cels and tanks.

The use of Liqui-Cel membrane contactors in the system design allows for rapid equilibration between the gas and seawater. Equilibration by bubbling can be quite slow depending on the volume of seawater needed (Schulz et al., 2009). 
Table 2. Average \pm standard deviation for chemical parameters during experiment S32. The $p\left(\mathrm{CO}_{2}\right), \Omega_{\mathrm{Calcite}}$, and $\Omega_{\text {Aragonite }}$ reported here were calculated using CO2calc (Robbins et al., 2010) with dissociation constants from Mehrbach et al. (1973) as refit by Dickson and Millero (1987). For most values $n=29-32$, except for oxygen for which some samples from each tank were lost (see Fig. 5).

\begin{tabular}{rllllllll}
\hline & $\begin{array}{l}\text { Temp } \\
\left({ }^{\circ} \mathrm{C}\right)\end{array}$ & Salinity & $\begin{array}{l}\text { Alkalinity } \\
\left(\mu \mathrm{mol} \mathrm{kg}{ }^{-1}\right)\end{array}$ & $\begin{array}{l}\mathrm{pH}_{(\mathrm{in} \mathrm{situ)}} \\
\text { total scale }\end{array}$ & $\begin{array}{l}\text { Oxygen } \\
\left(\mu \mathrm{mol} \mathrm{kg}^{-1}\right)\end{array}$ & $\begin{array}{l}\text { Calculated } p\left(\mathrm{CO}_{2}\right) \\
(\mu \mathrm{atm})\end{array}$ & $\begin{array}{l}\text { Calculated } \\
\Omega_{\mathrm{Calcite}}\end{array}$ & $\begin{array}{l}\text { Calculated } \\
\Omega_{\text {Aragonite }}\end{array}$ \\
\hline Treatment A & & & & & & & & \\
$\quad$ Replicate 1 & $11.2 \pm 0.5$ & $33.50 \pm 0.07$ & $2239.1 \pm 5.5$ & $7.923 \pm 0.035$ & $86.4 \pm 8.3$ & $540.7 \pm 48.7$ & $2.49 \pm 0.15$ & $1.58 \pm 0.10$ \\
Replicate 2 & $11.6 \pm 0.5$ & $33.51 \pm 0.05$ & $2241.8 \pm 4.5$ & $7.908 \pm 0.072$ & $83.0 \pm 12.9$ & $570.4 \pm 107.9$ & $2.46 \pm 0.32$ & $1.57 \pm 0.21$ \\
Treatment B & & & & & & & \\
Replicate 1 & $11.3 \pm 0.5$ & $33.49 \pm 0.07$ & $2241.1 \pm 5.8$ & $7.559 \pm 0.029$ & $241.1 \pm 9.1$ & $1337.3 \pm 97.4$ & $1.15 \pm 0.06$ & $0.73 \pm 0.04$ \\
Replicate 2 & $11.6 \pm 0.6$ & $33.51 \pm 0.06$ & $2244.2 \pm 7.1$ & $7.552 \pm 0.026$ & $241.7 \pm 7.6$ & $1364.2 \pm 88.1$ & $1.15 \pm 0.06$ & $0.73 \pm 0.04$ \\
\hline
\end{tabular}
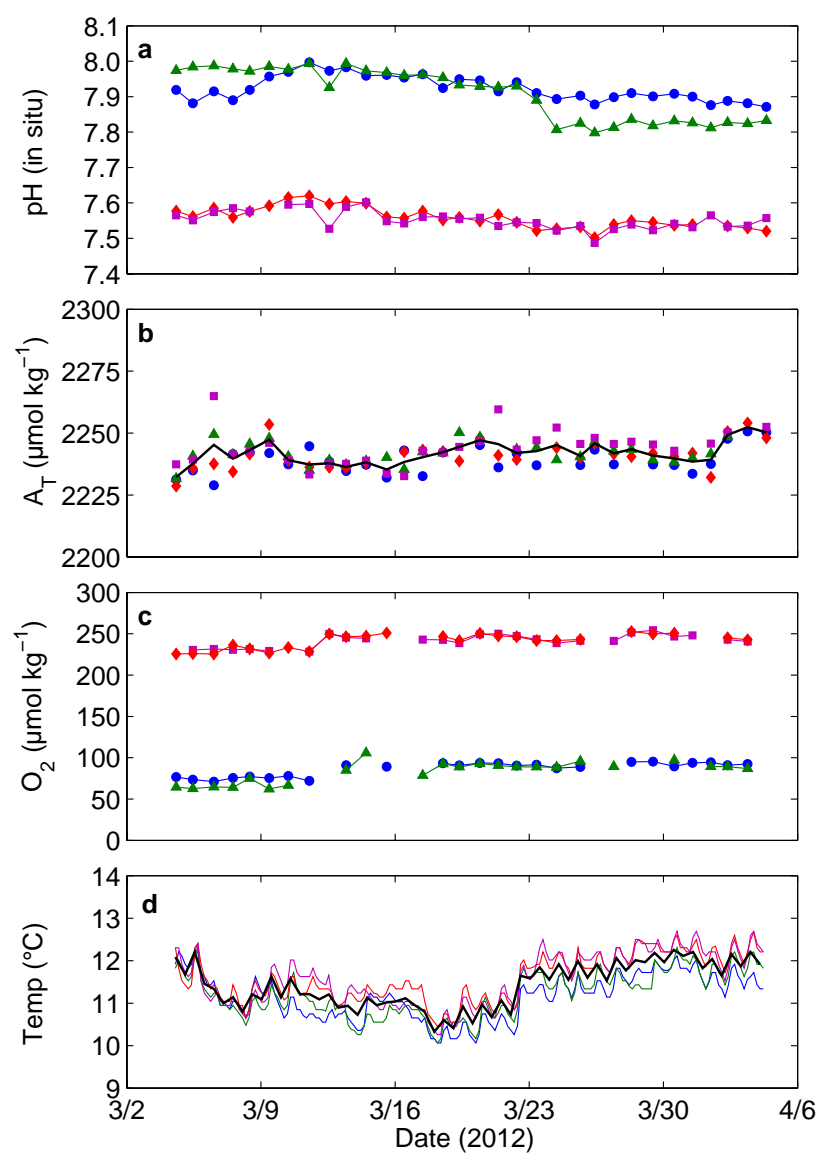

Fig. 5. Measured data from experiment $\mathrm{S} 32$. (a) $\mathrm{pH}$ : total $\mathrm{pH}$ scale; (b) $A_{\mathrm{T}}$ : the solid black line connects the daily average for all four tanks; (c) oxygen; and (d) temperature - the thick black line is the average of all tanks calculated at $12 \mathrm{~h}$ intervals. Symbols indicate discrete samples: Treatment A Replicate 1 (blue circles), Treatment A Replicate 2 (green triangles), Treatment B Replicate 1 (red diamonds), and Treatment B Replicate 2 (purple squares).

Membrane contactors also eliminate any concern over the direct impacts of bubbling on the experimental organism, and the continual cycling of the water through the Liqui-Cels allows for well-controlled experiments over a long time period.
The system is well suited to convert into one with feedback from chemical sensors in the individual aquaria, thus achieving a more active control over the carbonate chemistry. Such active control of each tank will allow for the transition of the system to one with intentional variability in each of the three controlled parameters. There is a growing need to understand the responses of organisms that live in variable environments, whether weekly, daily, or tidal timescales of variability, and how they may change in the future (Andersson and Mackenzie, 2012; Dufault et al., 2012).

MSEAS has been used successfully to study several organisms, life stages, and parameters. The flexibility of the system design has allowed for experimental organisms ranging from mussel larvae (C. A. Frieder, Experiment M7) to juvenile abalone (White, 2011) to adult oysters (M. Tresguerres, unpublished data, 2011). Experiments on moon jellies have been completed modifying only the oxygen levels in the seawater (Cawood, 2012), while in the experiment on adult oysters, $\mathrm{O}_{2}$ levels were held steady between treatments while $\mathrm{CO}_{2}$ concentration and temperature were modified. These examples indicate the large range of possible biological questions that can be examined using MSEAS, to expose a variety of species to future ocean conditions.

Acknowledgements. The authors thank the Birch Aquarium at Scripps Institution of Oceanography for generously making experimental space with seawater available to us; specifically Jeremy Lord for his assistance in the initial stages of design and setup. Thanks to Jen Gonzalez who was critical in the execution of experiments M7 and S32. This publication was prepared by Emily E. Bockmon under NOAA Grant \#NA08OAR4170669, California Sea Grant Project \#R/OPCENV-09, through NOAA's National Sea Grant College Program, US Dept. of Commerce; and was supported in part by the State of California Ocean Protection Council. Additionally, the National Science Foundation under Grant No. OCE-1039930 funded some equipment purchases and NSF Grant OCE-1041062 funded the biological experimental work. The statements, findings, conclusions and recommendations are those of the authors and do not necessarily reflect the views of the aforementioned organizations.

Edited by: H.-O. Pörtner 


\section{References}

Andersson, A. J. and Mackenzie, F. T.: Revisiting four scientific debates in ocean acidification research, Biogeosciences, 9, 893905, doi:10.5194/bg-9-893-2012, 2012.

Barry, J. P., Tyrrell, T., Hansson, L., Plattner, G.-K., and Gattuso, J.P.: Atmospheric $\mathrm{CO}_{2}$ targets for ocean acidification perturbation experiments, in: Guide to best practices for ocean acidification research and data reporting, edited by: Riebesell, U., Fabry, V. J., Hansson, L., and Gattuso, J.-P., Luxembourg, Publications Office of the European Union, 53-66, 2010.

Boyd, P. W.: Beyond ocean acidification, Nat. Geosci., 4, 273-274, doi:10.1038/ngeo1150, 2011.

Caldeira, K. and Wickett, M. E.: Anthropogenic carbon and ocean pH, Nature, 425, 365-365, doi:10.1038/425365a, 2003.

Cawood, A. M.: Laboratory and In Situ Investigations of Factors Affecting the Growth and Survivorship of the Scyphozoan Jellyfish Aurelia sp1, Doctoral Dissertation, Scipps Institution of Oceanography, UCSD, La Jolla, CA, 175 pp., 2012.

Dickson, A. G.: Determination of dissolved oxygen in sea water by Winkler titration, in: WOCE Operations Manual, Volume 3: The Observational Programme, Section 3.1: WOCE Hydrographic Programme. Part 3.1.3: WHP Operations and Methods, edited by: World Ocean Circulation Experiment, Woods Hole, Massachusetts, USA, 1-13, 1996.

Dickson, A. G.: The carbon dioxide system in seawater: equilibrium chemistry and measurements., in: Guide to best practices for ocean acidification research and data reporting., edited by: Riebesell, U., Fabry, V. J., Hansson, L., and Gattuso, J.-P., Luxembourg, Publications Office of the European Union, 17-40, 2010.

Dickson, A. G. and Millero, F. J.: A comparison of the equilibrium constants for the dissociation of carbonic acid in seawater media, Deep-Sea Res., 34, 1733-1743, doi:10.1016/01980149(87)90021-5, 1987.

Dickson, A. G., Sabine, C. L., and Christian, J. R.: Guide to best practices for ocean $\mathrm{CO}_{2}$ measurements, PICES Special Publication 3, 191, 2007.

Doney, S. C., Balch, W. M., Fabry, V. J., and Feely, R. A.: Ocean acidification: a critical emerging problem for the ocean sciences, Oceanography, 22, 16-25, 2009a.

Doney, S. C., Fabry, V. J., Feely, R. A., and Kleypas, J. A.: Ocean Acidification: The Other $\mathrm{CO}_{2}$ Problem, Annu. Rev. Mar. Sci., 1, 169-192, doi:10.1146/annurev.marine.010908.163834, 2009b.

Dufault, A. M., Cumbo, V. R., Fan, T. Y., and Edmunds, P. J.: Effects of diurnally oscillating $\mathrm{pCO}_{2}$ on the calcification and survival of coral recruits, Proc. R. Soc. B, 279, 2951-2958, doi:10.1098/rspb.2011.2545, 2012.

Fangue, N. A., O'Donnell, M. J., Sewell, M. A., Matson, P. G., MacPherson, A. C., and Hofmann, G. E.: A laboratory-based, experimental system for the study of ocean acidification effects on marine invertebrate larvae, Limnol. Oceanogr.-Meth., 8, 441452, doi:10.4319/lom.2010.8.441, 2010.

Feely, R. A., Sabine, C. L., Hernandez-Ayon, J. M., Ianson, D., and Hales, B.: Evidence for upwelling of corrosive "acidified" water onto the continental shelf, Science, 320, 1490-1492, doi:10.1126/science.1155676, 2008.

Frieder, C. A., Nam, S. H., Martz, T. R., and Levin, L. A.: High temporal and spatial variability of dissolved oxygen and $\mathrm{pH}$ in a nearshore California kelp forest, Biogeosciences, 9, 3917-3930, doi:10.5194/bg-9-3917-2012, 2012.

Gattuso, J.-P. and Lavigne, H.: Technical Note: Approaches and software tools to investigate the impact of ocean acidification, Biogeosciences, 6, 2121-2133, doi:10.5194/bg-6-21212009, 2009.

Gattuso, J.-P., Gao, K., Lee, K., Rost, B., and Schulz, K. G.: Approaches and tools to manipulate the carbonate chemistry, in: Guide to best practices for ocean acidification research and data reporting., edited by: Riebesell, U., Fabry, V. J., Hansson, L., and Gattuso, J.-P., Luxembourg: Publications Office of the European Union, 41-52, 2010.

Keeling, R. F., Kortzinger, A., and Gruber, N.: Ocean deoxygenation in a warming world, Annu. Rev. Mar. Sci., 2, 199-229, doi:10.1146/annurev.marine.010908.163855, 2010.

Lyman, J. M., Good, S. A., Gouretski, V. V., Ishii, M., Johnson, G. C., Palmer, M. D., Smith, D. M., and Willis, J. K.: Robust warming of the global upper ocean, Nature, 465, 334-337, doi:10.1038/nature09043, 2010.

McGraw, C. M., Cornwall, C. E., Reid, M. R., Currie, K. I., Hepburn, C. D., Boyd, P., Hurd, C. L., and Hunter, K. A.: An automated $\mathrm{pH}$-controlled culture system for laboratory-based ocean acidification experiments, Limnol. Oceanogr.-Meth., 8, 686-694, doi:10.4319/lom.2010.8.686, 2010.

Mehrbach, C., Culberson, C. H., Hawley, J. E., and Pytkowicz, R. M.: Measurement of apparent dissociation constants of carbonic acid in seawater at atmospheric pressure, Limnol. Oceanogr., 18, 897-907, 1973.

Melzner, F. T., Thomsen, J., Koeve, W., Oschlies, A., Gutowska, M. A., Bange, H. W., Hansen, H. P., and Körtzinger, A.: Future ocean acidification will be amplified by hypoxia in coastal habitats, Mar. Biol., doi:10.1007/s00227-012-1954-1, 2012.

Miller, A. W., Reynolds, A. C., Sobrino, C., and Riedel, G. F.: Shellfish Face Uncertain Future in High $\mathrm{CO}_{2}$ World: Influence of Acidification on Oyster Larvae Calcification and Growth in Estuaries, PLOS ONE, 4, e5661, doi:10.1371/journal.pone.0005661, 2009.

Nam, S., Kim, H. J., and Send, U.: Amplification of hypoxic and acidic events by La Nina conditions on the continental shelf off California, Geophys. Res. Lett., 38, L22602, doi:10.1029/2011g1049549, 2011.

Palacios, D. M., Bograd, S. J., Mendelssohn, R., and Schwing, F. B.: Long-term and seasonal trends in stratification in the California Current, 1950-1993, J. Geophys. Res.-Oceans, 109, C10016, doi:10.1029/2004jc002380, 2004.

Paulmier, A., Ruiz-Pino, D., and Garçon, V.: $\mathrm{CO}_{2}$ maximum in the oxygen minimum zone (OMZ), Biogeosciences, 8, 239-252, doi:10.5194/bg-8-239-2011, 2011.

Pörtner, H. O., Langenbuch, M., and Michaelidis, B.: Synergistic effects of temperature extremes, hypoxia, and increases in $\mathrm{CO}_{2}$ on marine animals: From Earth history to global change, J. Geophys. Res.-Oceans, 110, C09S10, doi:10.1029/2004jc002561, 2005.

Riebesell, U., Fabry, V. J., Hansson, L., and Gattuso, J. P.: Guide to best practices for ocean acidification research and data reporting, Luxembourg:, Publications Office of the European Union, 260 pp., 2010.

Robbins, L. L., Hansen, M. E., Kleypas, J. A., and Meylan, S. C.: $\mathrm{CO} 2$ calc - A user-friendly seawater carbon calculator for Windows, Mac OS X, and iOS(iPhone), US Geological Survey Open- 
File Report 2010-1280, 17, 2010.

Schulz, K. G., Barcelos e Ramos, J., Zeebe, R. E., and Riebesell, $\mathrm{U}$.: $\mathrm{CO}_{2}$ perturbation experiments: similarities and differences between dissolved inorganic carbon and total alkalinity manipulations, Biogeosciences, 6, 2145-2153, doi:10.5194/bg-6-21452009, 2009.

Shaffer, G., Olsen, S. M., and Pedersen, J. O. P.: Long-term ocean oxygen depletion in response to carbon dioxide emissions from fossil fuels, Nat. Geosci., 2, 105-109, doi:10.1038/ngeo420, 2009.

Shi, D., Xu, Y., and Morel, F. M. M.: Effects of the $\mathrm{pH} / p \mathrm{CO}_{2}$ control method on medium chemistry and phytoplankton growth, Biogeosciences, 6, 1199-1207, doi:10.5194/bg-6-1199-2009, 2009.
Talmage, S. C. and Gobler, C. J.: The effects of elevated carbon dioxide concentrations on the metamorphosis, size, and survival of larval hard clams (Mercenaria mercenaria), bay scallops (Argopecten irradians), and Eastern oysters (Crassostrea virginica), Limnol. Oceanogr., 54, 2072-2080, 2009.

Wernberg, T., Smale, D. A., and Thomsen, M. S.: A decade of climate change experiments on marine organisms: procedures, patterns and problems, Glob. Change Biol., 18, 1491-1498, doi:10.1111/j.1365-2486.2012.02656.x, 2012.

White, L. A.: The effects of ocean acidification and upwelling conditions on the growth and calcification of the red abalone (Haliotis rufescens), Master's Thesis, California State University San Marcos, San Marcos, CA, 55 pp., 2011.

Wolf-Gladrow, D. A., Zeebe, R. E., Klaas, C., Kortzinger, A., and Dickson, A. G.: Total alkalinity: The explicit conservative expression and its application to biogeochemical processes, Mar. Chem., 106, 287-300, doi:10.1016/j.marchem.2007.01.006, 2007. 